\title{
A Low-Cost Multiple Complementary Split-Ring Resonator Based Microwave Sensor for Contactless Dielectric Characterization of Liquids
}

\author{
Ahmed Javed, Ali Arif, Muhammad Zubair, Member IEEE, Muhammad Qasim Mehmood and Kashif Riaz
}

\begin{abstract}
We propose a low-cost, easy-to-fabricate, contactless microwave sensor for dielectric characterization of liquids. The design of the proposed sensor is based on a multiple complementary split-ring resonator (MCSRR) fabricated on a low-cost FR-4 substrate. A glass capillary tube having an inner diameter of $0.008 \lambda_{0}$ is inserted in the high electric field region of the MCSRR to carry the liquid under test. The sensor is designed to operate at a resonant frequency of $2.45 \mathrm{GHz}$ for an empty tube and shifted resonant peaks are utilized for the dielectric characterization of different liquids. The maximum observed shifts in resonant frequency and $Q$ factor are up to $400 \mathrm{MHz}$ and 31, respectively. The numerically established relations are experimentally verified through fabricated sensor for various binary mixtures of water and ethanol. The percentage errors between the calculated and reference permittivity of different samples are noticed to be less than $5 \%$. The proposed device promises to be a cost-effective and convenient solution for accurate dielectric characterization of liquids and their binary aqueous solutions.
\end{abstract}

Index Terms-Multiple complementary split ring resonator (MCSRR), microwave sensor, dielectric characterization, lowcost, liquid, binary mixture

\section{INTRODUCTION}

$\mathrm{M}$ ICROWAVE sensing is promising for diverse fields and applications due to its non-invasive and non-destructive nature [1]-[4]. These include (but not limited to) kinetic sensing [5], structural health monitoring [6], biosensing for biomedical and healthcare [4], dielectric characterization [7] and many more. Microwave sensors are becoming popular, in comparison to their optical and micro-electromechanical systems (MEMS) counterparts, due to their simplicity, cost-effectiveness, passivity and label-free sensing capability.

The quality of expensive liquids (e.g. ethanol) is often degraded by various contaminants (e.g. water). Hence, the detection of even small traces of contaminants in liquids is necessary to maintain their pureness. An accurate dielectric study of liquids can be used to distinguish pure liquids from contaminated ones [8]. Microwave sensors can be regarded as an economical choice for the sensing of liquids. Various microwave broadband techniques were adopted for this purpose [9], [10].

This work was supported in part by the Higher Education Commission (HEC), Pakistan under Grant TDF-03-160.

A. Javed, A. Arif, M. Zubair (email: muhammad.zubair@itu.edu.pk), M. Q. Mehmood (email: qasim.mehmood@itu.edu.pk) and K. Riaz (email: kashif.riaz@itu.edu.pk) are with the NanoTech Lab, Electrical Engineering Department, Information Technology University of the Punjab (ITU), Lahore 54600, Pakistan.

(Corresponding Authors: Muhammad Zubair, Muhammad Qasim Mehmood and Kashif Riaz)
The resonators-based sensors were preferred (over nonresonator ones) because of better accuracy within the narrow frequency band [11]. Different configurations of the microwave resonator sensors were employed for the dielectric characterization of liquids [12]-[14]. Cavity resonators were proposed to counter the problem of lower accuracy [15]-[17]. However, these cavity resonators were not only expensive but also required bulky experimental setups, hence making them incompatible for portable lab-on-a-chip and system-on-chip applications. Planar microwave resonators and metamaterial inspired resonators provided an ideal platform to realize compact sensors with high accuracy, high quality (Q) factor and enhanced sensitivity for such on-chip applications [18][20]. The appealing resonance characteristics of split-ring resonator (SRR) and complementary split-ring resonators (CSRR) enabled them to demonstrate several compact sensing applications [21]-[23]. However, the use of expensive substrates did not justify the low-cost claim of these demonstrations. This cost issue can be resolved by a careful design and optimization of resonators on a cheaper substrate like FR-4 (while compromising the Q factor within the acceptable limits). Owing to their unique resonance characteristics, these SRR and CSRR metamaterial inspired resonators were used in various other microwave applications, also including microfluidic-based sensing of liquids [23]-[29]. The polymer-based channels are prevalent among microfluidicbased microwave sensors for the liquid sensing. In [25], a single SRR excited by microstrip line was adopted for the dielectric characterization of aqueous liquid mixture, in which a polyethylene terephthalate (PET) film was used for the insertion of liquid samples inside the sensitive area of resonator fixed on a low-loss substrate, this work was extended in [26], where the dielectric characterization of liquid mixtures was carried out using a CSRR approach and liquids were flown onto the sensitive region using a polydimethylsiloxane (PDMS) channel. Many other researches also used polymer-based microfluidic channels [24]-[29], however, the fabrication of such microfluidic channels onto the substrate required a dedicated chemical procedure including, good texture molds, reagents and controlled environment to avoid bubble trapping and channel degradation. The polymer-based microfluidic channels not only add complications in fabrication process but also required additional time and effort. Various researches proposed a submersible technique to alleviate fabrication complexities for the detection of liquid samples in the microwave regime [30]-[32]. Such an approach required the device to be immersed into a liquid which consequently required larger sizes of liquid samples and also made the 
sensing mechanism invasive which is often not desired when dealing with costly chemicals. Moreover, the limited availability of expensive low-loss substrates emphasized the need of a relatively low-cost and easily available substrate for carrying out the sensing process.

In this work, an economical and easy-to-fabricate device is proposed to accurately characterize liquid samples based on their dielectric properties. A low-cost and label-free MCSRR based microwave sensor is demonstrated which is to be operated within Industrial, Scientific and Medical (ISM) band range at $2.45 \mathrm{GHz}$ frequency. Dielectric investigation on the binary mixture of water and ethanol is conducted experimentally using an accurate numerical model while, multiple samples of pure liquids having distinct and higher dielectric constants as compared to the binary mixture were used to further validate the sensitivity of the proposed sensor w.r.t the variation in the dielectric properties of liquid under test. The fabrication cost of the device is very low as FR-4 substrate is utilized and a conventional chemical etching is used for the fabrication. A simple, convenient and contactless method is researched and employed, for the detection of liquids, which includes a small glass capillary tube adjusted normal to the ground plane. The sensitivity of proposed device is noticed to be higher than a similar approach reported in [33], which is attributed to the use of a thicker substrate, thereby, increasing the influence of electric field on sample under test.

In the next section, design of proposed microwave sensor is introduced and modifications in basic structure of CSRR are explained with equivalent circuit model of the proposed MCSRR design. Section III describes the sensing principle of device. The fabricated prototype and experimental setup are depicted in section IV. Dielectric study and liquids responses are explained in section V and finally, the whole research is concluded in section VI.

\section{Design of the Proposed Sensor and its Equivalent CirCUIT MODELING}

\section{A. Proposed Design of the Sensor}

The structure of the proposed microwave sensor consists of a defected ground plane on one side (top) of the substrate (Fig. 1(a)), whereas a microstrip line is formed on the other side (bottom) of the substrate (Fig. 1(b)). The MCSRR is etched on ground plane, which is excited by the microstrip line (from its back-side) at a distance equal to the thickness of the substrate. The proposed MCSRR consists of four circular rings (hence, referred as MCSRR) having a defined split at opposite sides of consecutive rings. The electric field (of the applied electromagnetic signal) resonates the MCSRR in the axial direction. The CSRR is the complementary counterpart of SRR, in which rings of the resonator induces capacitance while the gap between them induces the inductance. This response is exactly opposite (as expected) to that of SRR. We preferred CSRR approach over SRR because it creates high electric field region between the resonator and microstrip line. This region can be effectively utilized for the sensing purpose. The electromagnetic simulations regarding the design and validation of MCSRR are carried out on CST Microwave Studio [34]. Wave ports are used for the excitation of MCSRR and $S_{21}$ plots are realized for the inspection of responses.

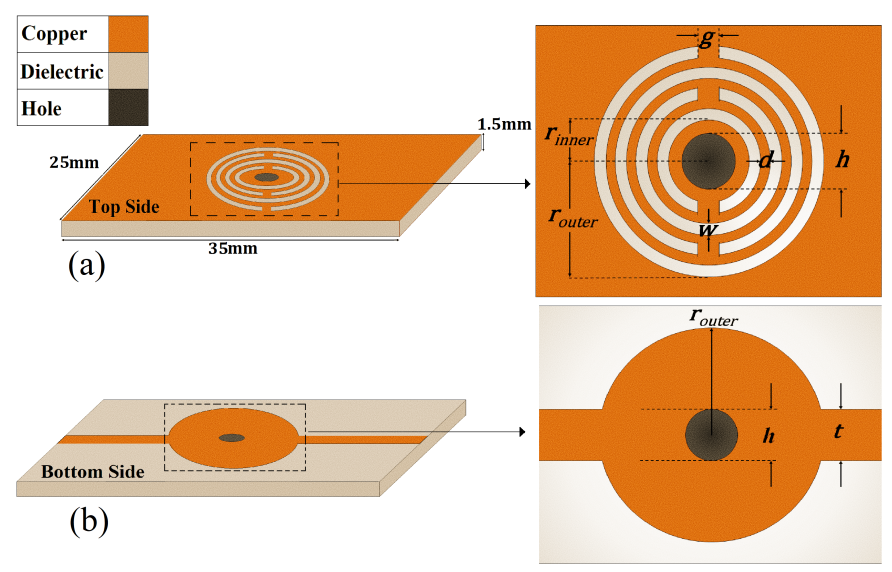

Fig. 1. Design of proposed microwave sensor along with different dimension parameters. (a) MCSRR on top side where the dimensions are: $r_{\text {outer }}=4.65 \mathrm{~mm}$, $r_{\text {inner }}=2.35 \mathrm{~mm}, g=0.7 \mathrm{~mm}, d=0.3 \mathrm{~mm}, w=0.35 \mathrm{~mm}, h=1.5 \mathrm{~mm}$ (b) Microstrip line on bottom side where $t=2.65 \mathrm{~mm}$, here effective permittivity and characteristic impedance of microstrip line are calculated as 3.3 and $50 \Omega$, respectively.

To achieve a higher attenuation and narrow bandwidth, a carefully optimized microstrip-ring (having a radius equal to the outer ring of MCSRR) is corrugated on the bottom side (in alignment with MCSRR) as depicted in Figure 1(b). It illustrates that a better resonance is achieved when the microstrip-ring is added in the structure.

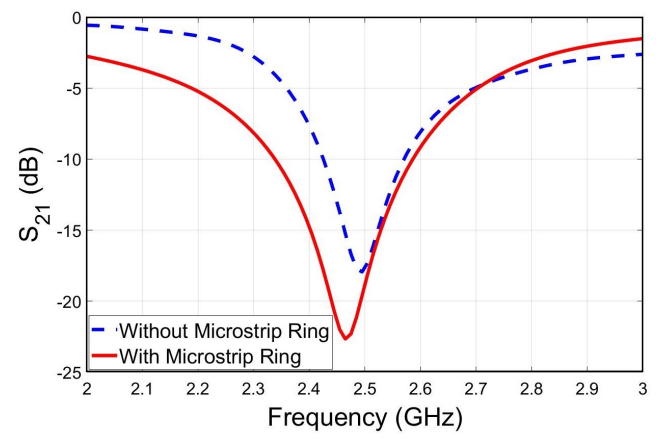

Fig. 2. Effect on the attenuation depth at resonance while using microstrip-ring for excitation of resonator whereas dotted line is showing the resonance without microstrip-ring.

It is observed (as expected) that the addition of more CSRR rings decreases the resonance frequency due to increase in its overall capacitance. This addition of more rings can be meticulously engineered to reduce the overall dimensions of the structure for a fixed resonance frequency. Meanwhile, it enhances the electric field localization between the MCSRR and microstrip-ring; hence enhancing its sensing capability. The effect of number of rings on the resonance frequency is simulated, and results (provided in Fig. 3) show that the addition of third and fourth rings introduces a frequency shift of about $80 \mathrm{MHz}$ in comparison to the two-ring CSRR. The results also show that with the integration of the fourth ring, the resonance frequency difference is minimal as compared to the 
three-ring structure. Therefore, further addition of rings is not necessary, or in other words, the addition of another ring would cause negligible increase in the capacitance of the MCSRR.

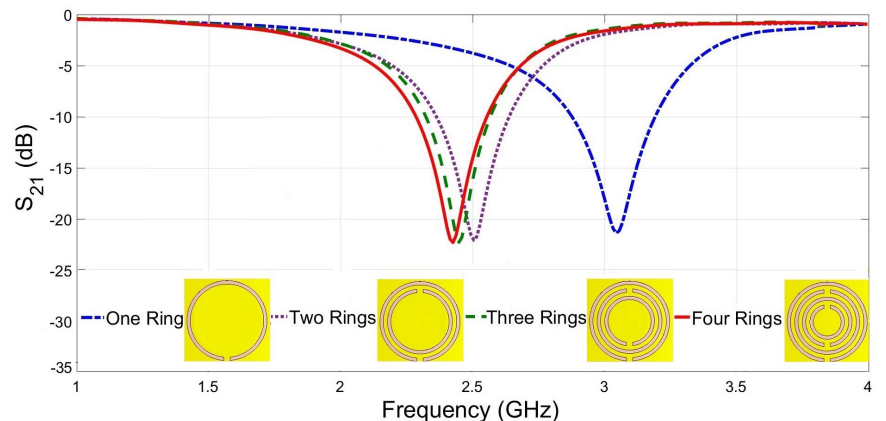

Fig. 3. Effect of increasing the number of rings in CSRR and the resonance frequency related to one, two, three and four rings.

\section{B. Equivalent Circuit Modeling}

The resonance frequency of MCSRR depends directly on the structural parameters of the resonator. Different parameters of MCSRR (i.e., size of the outer most ring ' router ', the distance between rings ' $d$ ', the gap in each ring ' $g$ ' and the width of each ring ' $w$ ') majorly influence capacitance and inductance of the resonator and collectively govern its resonance frequency. The investigation of the induced capacitance and inductance by the MCSRR is crucial to understand and predict its resonance behavior. Lumped element equivalent circuit modeling effectively explains this resonance behavior of MCSRR. An equivalent circuit modeling of CSRR was thoroughly studied in [35]. Its structure can be considered as a parallel combination of inductance and capacitance. Therefore, it acts as a band stop filter at resonance i.e.; it exhibits maximum attenuation.

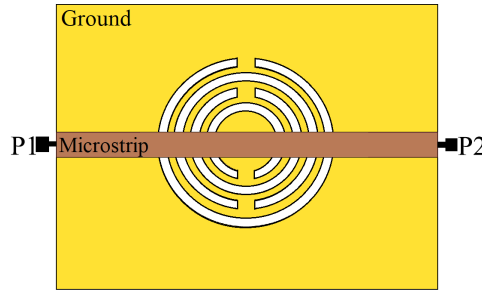

(a)

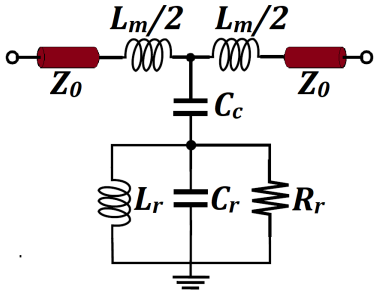

(b)
Fig. 4. Equivalent circuit model associated with MCSRR loaded microstrip line, where $\mathrm{C}_{\mathrm{r}}=0.75 \mathrm{pF}, \mathrm{C}_{\mathrm{c}}=0.5 \mathrm{pF}, \mathrm{L}_{\mathrm{r}}=3.5 \mathrm{nH}$ and $\mathrm{R}_{\mathrm{r}}=2350 \Omega$. (a) Schematic of different parts of sensor (b) Proposed equivalent circuit model associated with CSRR loaded microstrip line.

The equivalent circuit model is used to calculate the required dimensions of the proposed resonator to make it resonate at the desired frequency, given as [28],

$$
f_{r}=\frac{1}{2 \pi \sqrt{L_{r}\left(C_{r}+C_{c}\right)}},
$$

where ' $L_{r}$ ' and ' $C_{r}$ ' correspond to the inductance and capacitance of CSRR, respectively, while ' $C_{c}$ ' relates to the capacitance between ground plane and microstrip line. Furthermore in Fig. 4, ' $L_{m}$ ' represents the inductance of microstrip line and ' $Z_{0}$ ' is characteristic impedance of microstrip line which is adjusted at $50 \Omega$. The ' $R r$ ' refers to the resistance of the MCSRR and also depends upon the material under test, it is related to the $\mathrm{Q}$ factor, given as [26],

$$
Q=R_{r} \sqrt{\frac{\left(C_{r}+C_{c}\right)}{L_{r}}} .
$$

\section{SEnsing PrinciPLe}

The capacitive area of the device is basically the region where maximum electric field would be stored. In order to measure the dielectric properties of any dielectric substance, the sample should be placed in close vicinity to high electric field region of the sensor [36]. The capacitance of device will increase due to the placement of a dielectric material as electric field is now perturbed by the sample under test. The increase in capacitance will depend upon the complex permittivity offered by sample under test and the resonance frequency will undergo some reduction, as suggested by equation (1). Hence, the presence of any dielectric material can be detected through resonance frequency shift due to change in capacitance. Whereas, the lossy nature of dielectric substance is quantified by change in $\mathrm{Q}$ factor response. As the dielectric materials to be detected are liquids in our case, hence a medium is required to flow the liquid inside the high electric field region. As mentioned earlier, the polymer-based microfluidic channels are not desired in this research due to their complex fabrication problems, therefore we make use of a capillary tube.

In our sensor, the excitation through microstrip line produces high electric field region inside the substrate between MCSRR and microstrip line. At resonance, this region will become sensitive to dielectric changes in its vicinity and will show resonance shift.

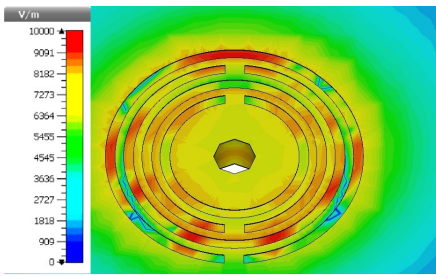

(a)

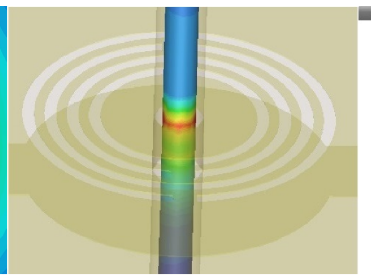

(b)
Fig. 6. Electric field distribution plot of sensor generated on CST. (a) Electric field plot of proposed MCSRR structure (b) Electric field influence on the sample residing inside capillary tube.

Mathematically, sensitivity of a resonator can be expressed in terms of change in resonance frequency due to a sample having relative permittivity ' $\varepsilon_{r}$ ', as given below [37]

$$
S=\frac{f_{\text {empty }}-f_{\text {sample }}}{f_{\text {empty }}\left(\varepsilon_{r}-1\right)} \times 100,
$$

where ' $f_{\text {empty }}$ ' and ' $f_{\text {sample }}$ ' refer to resonance frequency when capillary tube is kept empty and filled with liquid sample, respectively and ' $S$ ' refers to sensitivity. A glass capillary tube is adjusted inside a hole created in middle of MCSRR. The electric 
field distribution plots in Fig. 6 show that the liquid sample residing inside the hole is influenced by high electric field.

\section{FABRICATION AND EXPERIMENTAL SETUP}

Due to its low cost and easy availability, the substrate chosen for the fabrication of proposed design is FR-4 having relative permittivity of 4.3 and thickness of $1.5 \mathrm{~mm}$. The copper thickness for ground plane and microstrip line is $35 \mu \mathrm{m}$. The fabricated prototype is shown in Fig. 7. The dimensions of fabricated MCSRR are kept the same as suggested through equivalent circuit and simulated model. The connection of sensor with the ports of NI PXIE-5630 vector network analyzer (VNA) is done through Sub-Miniature Version A (SMA) connectors soldered at both ends of the microstrip line. The VNA is calibrated using Anritsu K calibration kit 3752L prior to experiments. A glass capillary tube having $1.5 \mathrm{~mm}$ outer diameter and $1 \mathrm{~mm}$ inner diameter is adjusted inside a $0.75 \mathrm{~mm}$ radius hole drilled in middle of the device.
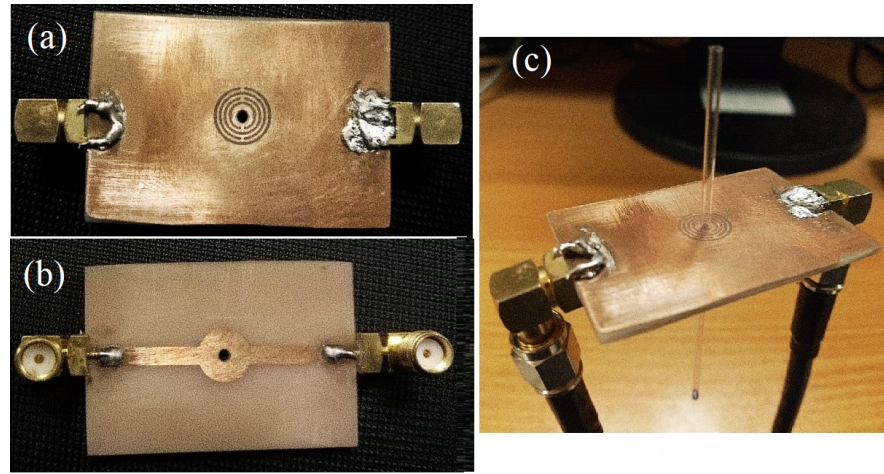

Fig. 7. Fabricated prototype. (a) Top side containing proposed MCSRR structure (b) Bottom side containing microstrip line for excitation (c) Side view with capillary tube inserted through the hole.

The liquids are injected from top of the capillary tube and collected from the bottom to avoid chemical wastage. The testing of each chemical sample is done with a separate capillary tube to ensure purity. Furthermore, the absence of any other electronic device near the VNA is made sure, thereby reducing the errors due to electromagnetic interference. The temperature for all the measurements was maintained at $20^{\circ} \mathrm{C}$, so that chemicals must not alter their responses due to temperature change. It can be seen in Fig. 8 that the experimentation on multiple liquid samples can be done in a rather easier yet quick way.
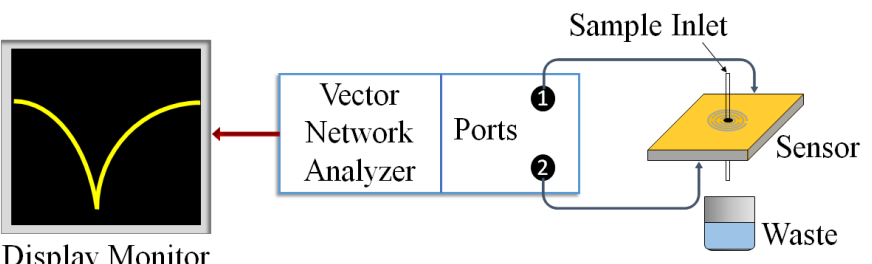

Fig. 8. Schematic diagram of the experimental setup used for the liquid sensing.

A strong agreement between the resonance of equivalent circuit, simulated model and experimental device has been noticed that validates the performance of our fabricated device.
The comparison between results of fabricated and simulated device is depicted in Fig. 9.

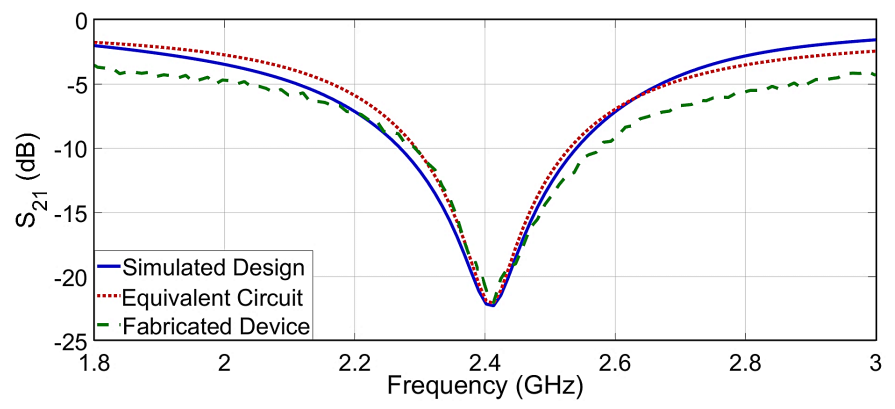

Fig. 9. Resonance frequency (without placing capillary tube) agreement of fabricated device with the results of equivalent circuit and simulated model.

\section{RESUlTS AND Discussions}

\section{A. Dielectric Study of Binary Mixture of Water-Ethanol}

Different concentrations of ethanol are added in distilled water for the study of dielectric properties associated with their binary mixtures. The step size of ethanol concentration increment in water is taken as $20 \%$. The selected percentages of ethanol to be added in water are $10 \%, 30 \%, 50 \%, 70 \%$, and $90 \%$. A pipette is used for the preparation of samples containing accurate measurement of mentioned concentrations of ethanol in water. The pipette was dried off after every measurement and it was ensured that there is no remaining droplet (of the previous mixture) before performing the next measurement to avoid contamination.

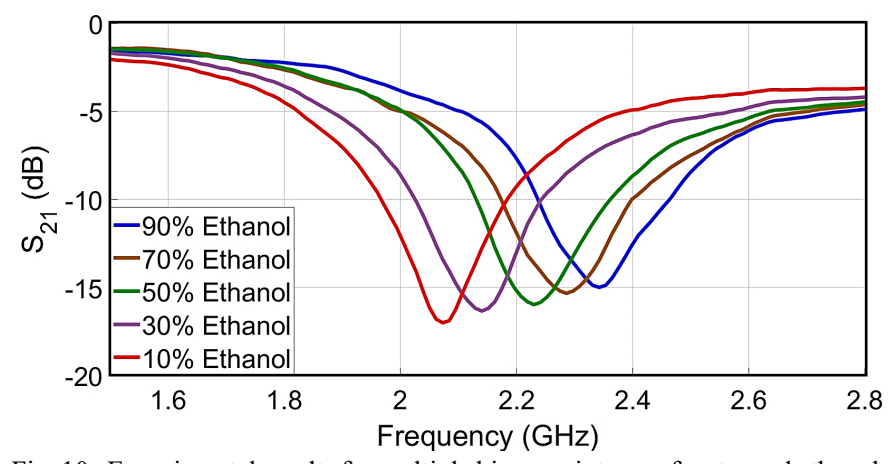

Fig. 10. Experimental results for multiple binary mixtures of water and ethanol, where the percentage of ethanol is changed between $10 \%$ to $90 \%$ with $20 \%$ step size.

The resonance frequency increased to higher values (less shift) when the concentration of ethanol was increased in water. The trend remained same throughout the experimentation process. But the response of Q factor was rather non-linear with respect to concentration change of ethanol in water. It is due to the non-linear loss function of the water mixture [26]. It has been observed that the $\mathrm{Q}$ factor shifted to lower values as concentration of ethanol was gradually increased. The minimum $Q$ factor of the mixture was achieved for $70 \%$ ethanol in $30 \%$ water and with further increase in ethanol concentration, the Q factor showed slight increase. The resonance frequency change was between $2.345 \mathrm{GHz}$ and $2.072 \mathrm{GHz}$, with former being for $90 \%$ ethanol and latter for $10 \%$ ethanol (Fig. 10). The linear relation of frequency and non-linear relation of $\mathrm{Q}$ factor 
with the changing concentration of ethanol in water is depicted in Fig. 11. The detail of measured responses for different percentages of the binary mixture is being listed in Table I.

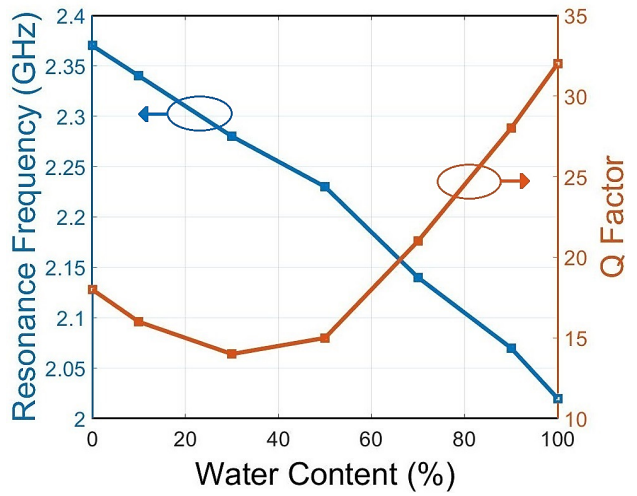

Fig. 11. Relation of $\mathrm{Q}$ factor and resonance frequency with changing concentrations of ethanol in water. "Center Frequency/Bandwidth" is used for $\mathrm{Q}$ factor calculation where bandwidth of $-3 \mathrm{~dB}$ with respect to the minimal transmission is considered.

TABLE I

DETAIL OF RESONANCE FREQUENCY, ATTENUATION DEPTH AND Q FACTOR ASSOCIATED WITH DifFERENT PERCENTAGES OF WATER-ETHANOL MIXTURE

\begin{tabular}{ccccc}
\hline \hline $\begin{array}{c}\text { Water } \\
\text { Percentage }\end{array}$ & $\begin{array}{c}\text { Ethanol } \\
\text { Percentage }\end{array}$ & $\begin{array}{c}\text { Resonance } \\
\text { Frequency } \\
(\mathrm{GHz})\end{array}$ & $\begin{array}{c}\text { Attenuation } \\
\text { Depth }(\mathrm{dB})\end{array}$ & Q factor \\
\hline $90 \%$ & $10 \%$ & 2.071 & -18.1 & 28 \\
$70 \%$ & $30 \%$ & 2.143 & -16.8 & 21 \\
$50 \%$ & $50 \%$ & 2.231 & -16.2 & 15 \\
$30 \%$ & $70 \%$ & 2.282 & -15.3 & 14 \\
$10 \%$ & $90 \%$ & 2.343 & -15.5 & 16 \\
\hline \hline
\end{tabular}

The calculation of complex permittivity $\left(\varepsilon^{\prime}+j \varepsilon^{\prime \prime}\right)$ for different concentrations of ethanol in water is determined using the least square method. The change in resonance frequency and Q factor are basically functions of complex permittivity associated with changing concentration of the binary mixture. The reference values of complex permittivity for different concentrations of water-ethanol mixtures are taken from [38]. The model describing change in frequency and Q factor with respect to complex permittivity of the sample is defined by a set of linear equations, which are

$$
\begin{gathered}
\Delta f_{r e s}=a \Delta \varepsilon^{\prime}+b \Delta \varepsilon^{\prime \prime}, \\
\Delta Q=c \Delta \varepsilon^{\prime}+d \Delta \varepsilon^{\prime \prime} .
\end{gathered}
$$

The factors ' $a$ ', ' $b$ ', ' $c$ ' and ' $d$ ' given in (4) and (5) are unknown coefficients that will define a complete relation of dependence of resonance frequency and $\mathrm{Q}$ factor with complex permittivity of samples, once they are calculated accurately. Change in complex permittivity ' $\Delta \varepsilon$ ', resonance frequency ' $\Delta f_{\text {res }}$ ' and $\mathrm{Q}$ factor ' $\Delta Q$ ' are calculated with the reference values (of respective parameters) taken for the sample containing $50 \%$ of ethanol in water and are given as

$$
\begin{gathered}
\Delta \varepsilon=\varepsilon_{\text {sam }}-\varepsilon_{\text {ref }}, \\
\Delta f_{\text {res }}=f_{\text {sam }}-f_{\text {ref }},
\end{gathered}
$$

$$
\Delta Q=Q_{\text {sam }}-Q_{\text {ref }} .
$$

A matrix model is defined for the mathematical analysis of finding the unknown coefficients which is given by

$$
\left[\begin{array}{c}
\Delta f_{\text {res }} \\
\Delta Q
\end{array}\right]=\left[\begin{array}{ll}
a & b \\
c & d
\end{array}\right]\left[\begin{array}{c}
\Delta \varepsilon^{\prime} \\
\Delta \varepsilon^{\prime \prime}
\end{array}\right]
$$

The concentrations of ethanol in the aqueous binary mixture considered for the derivation of the mathematical model are $0 \%, 10 \%, 30 \%, 50 \%, 70 \%, 90 \%$, and $100 \%$. As, number of samples are more than the number of unknowns, hence the system becomes over-determined. The shifts in resonance frequency and $\mathrm{Q}$ factor belonging to different samples of waterethanol mixture are incorporated in tall matrices. ' $X$ ', ' $Y$ ' and ' $Z$ ' matrices are defined for the values regarding change in complex permittivity, resonance frequency and $\mathrm{Q}$ factor respectively, which are as follows

$$
\begin{gathered}
X=\left[\begin{array}{cc}
\Delta \varepsilon_{1}{ }^{\prime} & \Delta \varepsilon_{1}^{\prime \prime} \\
\Delta \varepsilon_{2}{ }^{\prime} & \Delta \varepsilon_{2}^{\prime \prime} \\
\Delta \varepsilon_{3}{ }^{\prime} & \Delta \varepsilon_{3}^{\prime \prime} \\
\vdots & \vdots \\
\Delta \varepsilon_{7}{ }^{\prime} & \Delta \varepsilon_{7}^{\prime \prime}
\end{array}\right]=\left[\begin{array}{cc}
36 & -7.9 \\
30 & -5.8 \\
15.5 & 0 \\
0 & 0 \\
-14 & -1.1 \\
-27 & -5.1 \\
-34 & -9
\end{array}\right], \\
Y=\left[\begin{array}{c}
\Delta \mathrm{f}_{1} \\
\Delta \mathrm{f}_{2} \\
\Delta \mathrm{f}_{3} \\
\vdots \\
\Delta \mathrm{f}_{7}
\end{array}\right]=\left[\begin{array}{c}
-0.21 \\
-0.16 \\
-0.09 \\
0 \\
0.05 \\
0.11 \\
0.14
\end{array}\right] \&, Z=\left[\begin{array}{c}
\Delta Q_{1} \\
\Delta Q_{2} \\
\Delta Q_{3} \\
\vdots \\
\Delta Q_{7}
\end{array}\right]=\left[\begin{array}{c}
17 \\
13 \\
6 \\
0 \\
-1 \\
1 \\
2
\end{array}\right] .
\end{gathered}
$$

These values are calculated for the seven mentioned mixture samples of water-ethanol. Knowing that, the initial matrix form provided in (9) can be rewritten as

$$
\left[\begin{array}{ll}
\mathrm{Y} & \mathrm{Z}
\end{array}\right]^{\mathrm{T}}=\left[\begin{array}{ll}
\mathrm{a} & \mathrm{b} \\
\mathrm{c} & \mathrm{d}
\end{array}\right][\mathrm{X}]^{\mathrm{T}} .
$$

Now, we only need to apply pseudo inversion upon the updated matrix (10) and the unknowns can be found as

$$
\begin{aligned}
& {\left[\begin{array}{ll}
\mathrm{a} & \mathrm{b}
\end{array}\right]^{\mathrm{T}}=\left(\mathrm{X}^{\mathrm{T}} \mathrm{X}\right)^{-1} \cdot \mathrm{X}^{\mathrm{T}} \mathrm{Y}} \\
& {\left[\begin{array}{ll}
\mathrm{c} & \mathrm{d}
\end{array}\right]^{\mathrm{T}}=\left(\mathrm{X}^{\mathrm{T}} \mathrm{X}\right)^{-1} \cdot \mathrm{X}^{\mathrm{T}} \mathrm{Z}}
\end{aligned}
$$

Equations (11) and (12) generate the values of unknown coefficients and are given as

$$
\left[\begin{array}{ll}
\mathrm{a} & \mathrm{b} \\
\mathrm{c} & \mathrm{d}
\end{array}\right]=\left[\begin{array}{rr}
-0.0049 & 0.0036 \\
0.2195 & -1.1764
\end{array}\right] .
$$

These calculated coefficients are used in the original matrix model to find complex permittivity of any particular sample provided a change in frequency and $\mathrm{Q}$ factor associated with the given sample are already calculated. The final matrix that provides the dielectric information of different water-ethanol samples is given as 


$$
\left[\begin{array}{cc}
-235.3 & -0.7237 \\
-44.2 & -0.9851
\end{array}\right]\left[\begin{array}{c}
\Delta \mathrm{f}_{\text {res }} \\
\Delta \mathrm{Q}
\end{array}\right]=\left[\begin{array}{c}
\Delta \varepsilon^{\prime} \\
\Delta \varepsilon^{\prime \prime}
\end{array}\right]
$$

It can be seen in Fig. 12 that our calculated values of both real and imaginary parts of permittivity are in reasonable agreement with the literature results.

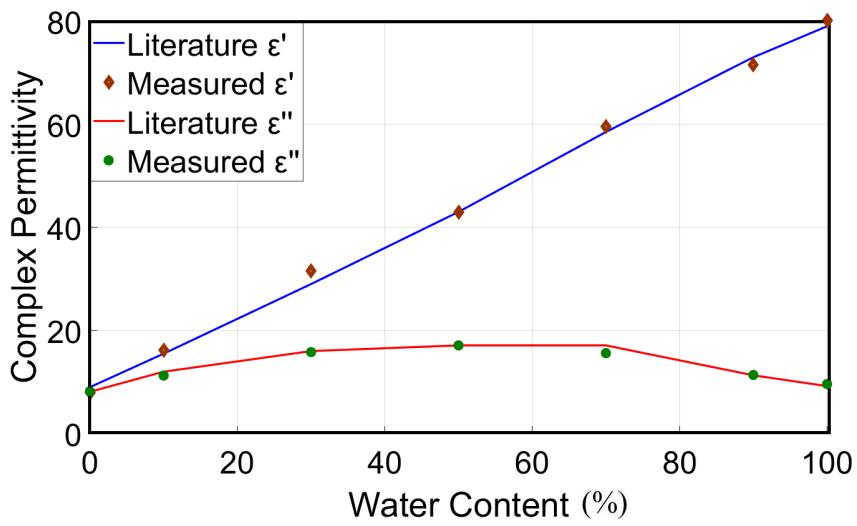

Fig. 12. Comparison between measured values of complex permittivity for different concentrations of water-ethanol mixtures (intended for calibration of sensor) with the reference values found in [38] at $2.4 \mathrm{GHz}$.

Now that we have calibrated the sensor for the mathematical model given in equation (14), a second set of water-ethanol samples ranging from $20 \%$ to $80 \%$ with a $20 \%$ step size are considered to validate the performance of the sensor and the accuracy of defined mathematical model, the results for the second set of samples are depicted in Fig. 13. The maximum calculated percentage errors between measured and reference values of real and imaginary permittivity are $4.9 \%$ and $4.6 \%$, respectively, which might be due to experimental uncertainties and first order approximations.

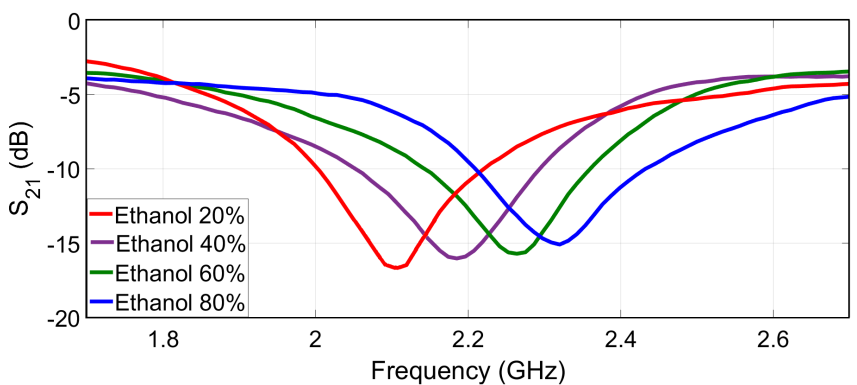

(a)

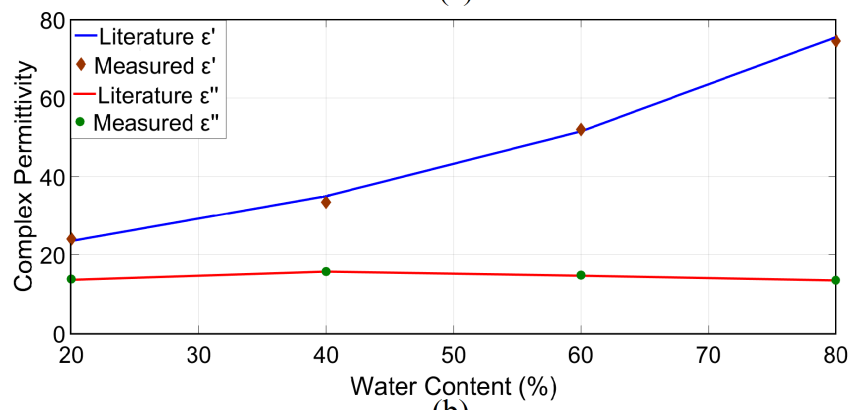

(b)

Fig. 13. Experimental results of $20 \%-80 \%$ mixtures of ethanol in water with a $20 \%$ step size, intended for validation of the mathematical model. (a) Measured responses of water-ethanol mixtures (b) Comparison between reference values [38] and calculated values of complex permittivity from equation (14).

\section{B. Experimental Results of Pure Liquid Samples}

To further validate the sensitivity of the proposed sensor, the study has been extended for other liquids having distinct and higher dielectric constants as compared to binary mixture of water and ethanol. Simulation and experimentation on absolute butanol $\left(\varepsilon_{\mathrm{r}}=3.5\right)$, absolute ethanol $\left(\varepsilon_{\mathrm{r}}=9.0\right)$, absolute methanol $\left(\varepsilon_{\mathrm{r}}=21.3\right)$ and distilled water $\left(\varepsilon_{\mathrm{r}}=79.0\right)$ are done and their responses are recorded. Clear shifts in resonance frequency and Q factors were noticed during the simulation as well as experimental analysis of these liquids and the results are shown in Fig. 14.

The maximum resonance frequency shift of approximately $400 \mathrm{MHz}$ (as compared to empty capillary tube case) was noticed for the case of distilled water as largest capacitance is offered by water due to its highest permittivity among other mentioned liquids. On the other hand, insertion of butanol caused a shift of about $25 \mathrm{MHz}$ in resonance frequency which was recorded as lowest resonance shift. The maximum $\mathrm{Q}$ factor of 45 was achieved when no liquid was placed in the capillary tube, whereas the minimum $\mathrm{Q}$ factor was noticed when methanol was flown in the capillary tube which came out to be 13. The measured results are in a strong agreement with the simulated results that validate the experimental responses of our device for different liquids. The simulated and experimental responses of different pure liquid samples used in this research are listed in Table II.

Finally, the performance and important features of the proposed device are compared with some related state of art researches (Table III) which proves our claim of providing a cost-effective and easy-to-fabricate method for considerably good analysis on liquid samples.

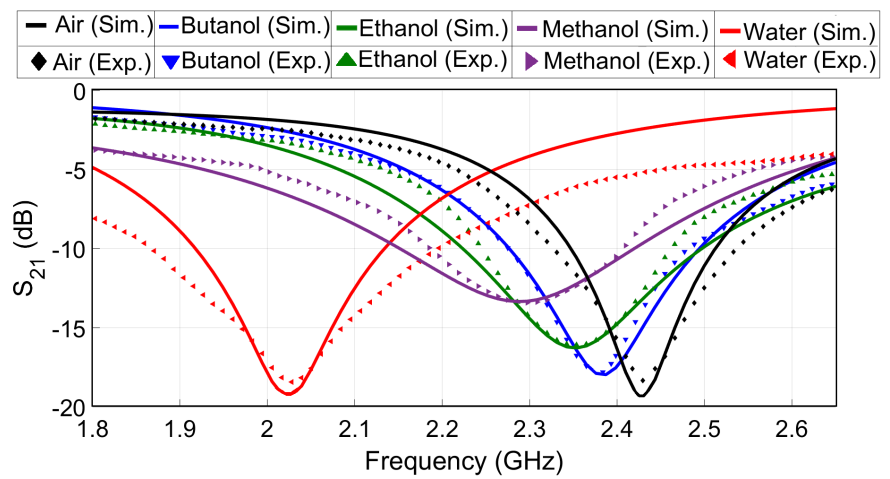

Fig. 14. Experimental and simulated results of air, pure butanol, pure ethanol, pure methanol and distilled water.

TABLE II

COMPARISON BETWEen SIMULATED RESUlts OF DifFERENT PURE LiQUid SAMPLES WITH MEASURED RESULTS

\begin{tabular}{ccccc}
\hline \hline Sample & $\begin{array}{c}\text { Simulated } \\
\text { Res. Freq. } \\
(\mathrm{GHz})\end{array}$ & $\begin{array}{c}\text { Simulated } \\
\text { Q Factor }\end{array}$ & $\begin{array}{c}\text { Measured } \\
\text { Res. Freq. } \\
(\mathrm{GHz})\end{array}$ & $\begin{array}{c}\text { Measured } \\
\text { Q Factor }\end{array}$ \\
\hline Air & 2.4191 & 46 & 2.4192 & 45 \\
Butanol & 2.3883 & 31 & 2.3870 & 32 \\
Ethanol & 2.3704 & 17 & 2.3705 & 18 \\
Methanol & 2.2998 & 10 & 2.3011 & 13 \\
Distilled Water & 2.0209 & 38 & 2.0211 & 31 \\
\hline \hline
\end{tabular}


TABLE III

Comparison of Proposed DeVice With State of ARt Microwave Sensors Used For Dielectric Characterization of Aqueous Binary MiXTuRes

\begin{tabular}{|c|c|c|c|c|c|c|c|c|c|}
\hline \multirow{2}{*}{ Ref. } & \multirow{2}{*}{$\begin{array}{l}\text { Res. } \\
\text { Freq. } \\
\text { (GHz) }\end{array}$} & \multirow{2}{*}{ Substrate } & \multicolumn{2}{|c|}{ Size $\mathrm{L} \times \mathrm{W} \times \mathrm{H}(\mathrm{mm})$} & \multirow{2}{*}{$\begin{array}{c}\text { Liquid } \\
\text { Flow } \\
\text { Mechanism }\end{array}$} & \multirow{2}{*}{$\begin{array}{c}\text { Sample } \\
\text { Volume } \\
(\mu \mathrm{L})\end{array}$} & \multirow{2}{*}{$\begin{array}{c}\text { Max. } \\
\text { Sensitivity }\end{array}$} & \multirow{2}{*}{ Fabrication } & \multirow{2}{*}{ Cost } \\
\hline & & & Actual Size & Electrical Size & & & & & \\
\hline$[28]$ & 2 & Rogers RT6002 & $40 \times 30 \times 3$ & $0.26 \lambda_{0} \times 0.2 \lambda_{0} \times 0.02 \lambda_{0}$ & PDMS & 0.39 & 0.436 & Complex & High \\
\hline$[27]$ & 1 & Rogers RO3010 & $86 \times 62 \times 13.2$ & $0.29 \lambda_{0} \times 0.21 \lambda_{0} \times 0.04 \lambda_{0}$ & PET film & 170 & 0.195 & Complex & High \\
\hline$[33]$ & 2.4 & Rogers RO3035 & $20 \times 28 \times 1$ & $0.16 \lambda_{0} \times 0.22 \lambda_{0} \times 0.08 \lambda_{0}$ & $\begin{array}{c}\text { Capillary } \\
\text { Tube }\end{array}$ & 1.325 & 0.036 & Easy & Moderate \\
\hline$[30]$ & 5.8 & F4B-2 & $75 \times 33 \times 1$ & $1.47 \lambda_{0} \times 0.64 \lambda_{0} \times 0.19 \lambda_{0}$ & Submersible & 500000 & 0.102 & Moderate & Moderate \\
\hline
\end{tabular}

\section{CONCLUSION}

In this research, a low-cost, contactless, label-free, easy-tofabricate and compact MCSRR based microwave sensor has been presented which is used for discriminating multiple proportions of water in ethanol by accurately measuring the complex permittivity of different samples of the binary mixture, where the complex permittivity of a particular mixture can be calculated as derived in the form of expression given by equation (14). The design of proposed device consisted of MCSRR on ground plane excited by microstrip line placed at the opposite side of the substrate. Capillary tube inserted in a drilled hole in middle of MCSRR is used for the liquid flow through high electric field region. The use of capillary tube and FR-4 substrate make the whole sensing procedure lessexpensive and less-cumbersome as compared to other related researches. A dielectric study of water-ethanol mixtures was conducted using least square method. The percentage errors between measured and reference values of complex permittivity for the binary mixtures of water-ethanol were noticed to be less than $5 \%$. To further validate the sensitivity of the proposed sensor with respect to the change in dielectric properties of liquids having higher permittivity differences than binary mixture of water-ethanol, absolute liquids of butanol, ethanol, methanol and distilled water were tested. Each liquid showed a clear shift in resonance frequency and $\mathrm{Q}$ factor according to the dielectric properties it possessed. It can be concluded that the proposed MCSRR based microwave sensor is a good candidate for accurate dielectric characterization of liquid samples while offering a low-cost and easy operation. However, as part of future work, the authors are dedicated towards enhancing the sensitivity without substantially increasing the cost of the sensing system, thereby quantifying the purity of some important domestically used liquids such as milk, oil etc. Moreover, resolution of sensor being an important parameter, especially when dealing with very small yet crucial changes in liquid permittivity (due to contamination), will be part of our future researches.

\section{REFERENCES}

A. P. Gregory and R. N. Clarke, "A review of RF and microwave techniques for dielectric measurements on polar liquids," IEEE Trans. Dielectr. Electr. Insul., vol. 13, no. 4, pp. 727-743, 2006.

[2] A. A. Helmy et al., "A self-sustained CMOS microwave chemical sensor using a frequency synthesizer," IEEE J. Solid-State Circuits, vol. 47, no. 10, pp. 2467-2483, 2012.
[3] Devendra Misra, Mohinder Chabbra, Benjamin R. Epstein, Mark Mirotznik, and Kenneth R. Foster, "Noninvasive Electrical Characterization of Materials at Microwave Frequencies Using an Open-Ended Coaxial Line: Test of an Improved Calibration Technique," IEEE Trans. Microw. Theory Tech., vol. 38, no. 1, pp. 8-14, 1990.

[4] M. Nakamura, T. Tajima, M. Seyama, and K. Waki, "A noninvasive blood glucose measurement by microwave dielectric spectroscopy: Drift correction technique," in IMBioc 2018 - 2018 IEEE/MTT-S International Microwave Biomedical Conference, 2018, vol. 1, pp. $85-87$.

[5] J. Naqui, M. Durán-Sindreu, and F. Martín, "Alignment and position sensors based on split ring resonators," Sensors (Switzerland), vol. 12, no. 9, pp. 11790-11797, 2012.

[6] B. S. Cook, A. Shamim, and M. M. Tentzeris, "Passive low-cost inkjet-printed smart skin sensor for structural health monitoring," IET Microwaves, Antennas Propag., vol. 6, no. 14, pp. 1536-1541, 2012.

[7] A. Soffiatti, Y. Max, S. G. Silva, and L. M. de Mendonça, "Microwave metamaterial-based sensor for dielectric characterization of liquids," Sensors (Switzerland), vol. 18, no. 5, 2018.

[8] A. Salim and S. Lim, "Complementary split-ring resonator-loaded microfluidic ethanol chemical sensor," Sensors (Switzerland), vol. 16 , no. $11,2016$.

[9] A. Nyshadham, C. L. Sibbald, and S. S. Stuchly, "Permittivity Measurements using Open-Ended Sensors and Reference Liquid Calibration - an Uncertainty Analysis," IEEE Trans. Microw. Theory Tech., vol. 40, no. 2, pp. 305-314, 1992.

[10] U. Kaatze and Y. Feldman, "Broadband dielectric spectrometry of liquids and biosystems," Meas. Sci. Technol., vol. 17, no. 2, 2006.

[11] L. Su, J. Mata-Contreras, P. Vélez, A. Fernández-Prieto, and F. Martín, "Analytical method to estimate the complex permittivity of oil samples," Sensors (Switzerland), vol. 18, no. 4, pp. 1-12, 2018.

[12] L. Su, J. Mata-Contreras, P. Vélez, and F. Martín, "Splitter / Combiner Microstrip Sections Loaded With Pairs of Complementary Split Ring Resonators Differential Sensing Applications," IEEE Trans. Microw. Theory Tech., vol. 64(12), pp. 4362-4370, 2016.

[13] C. L. Yang, C. Sen Lee, K. W. Chen, and K. Z. Chen, "Noncontact measurement of complex permittivity and thickness by using planar resonators," IEEE Trans. Microw. Theory Tech., vol. 64, no. 1, pp. 247-257, 2016.

[14] P. Velez, K. Grenier, J. Mata-Contreras, D. Dubuc, and F. Martin, "Highly-sensitive microwave sensors based on Open Complementary Split Ring Resonators (OCSRRs) for dielectric characterization and solute concentration measurement in liquids," IEEE Access, vol. 6, no. c, pp. 48324-48338, 2018.

[15] G. Gennarelli, S. Romeo, M. R. Scarfi, and F. Soldovieri, "A microwave resonant sensor for concentration measurements of liquid solutions," IEEE Sens. J., vol. 13, no. 5, pp. 1857-1864, 2013.

[16] A. H. Sklavounos and N. S. Barker, "Liquid-permittivity measurements using a rigorously modeled overmoded cavity resonator," IEEE Trans. Microw. Theory Tech., vol. 62, no. 6, pp. 1363-1372, 2014.

[17] H. Guo, L. Yao, and F. Huang, "A cylindrical cavity sensor for liquid water content measurement," Sensors Actuators, A Phys., vol. 238, pp. 133-139, 2016.

[18] C. Sen Lee and C. L. Yang, "Complementary split-ring resonators for measuring dielectric constants and loss tangents," IEEE Microw. Wirel. Components Lett., vol. 24, no. 8, pp. 563-565, 2014. 
T. Chretiennot, D. Dubuc, and K. Grenier, "A Microwave and microfluidic planar resonator for efficient and accurate complex permittivity characterization of aqueous solutions," IEEE Trans. Microw. Theory Tech., vol. 61, no. 2, pp. 972-978, 2013.

[20] M. S. Boybay and O. M. Ramahi, "Material characterization using complementary split-ring resonators," IEEE Trans. Instrum. Meas., vol. 61, no. 11, pp. 3039-3046, 2012.

[21] W. Withayachumnankul, K. Jaruwongrungsee, C. Fumeaux, S. Member, and D. Abbott, "Metamaterial-Inspired Multichannel ThinFilm Sensor," vol. 12, no. 5, pp. 1455-1458, 2012.

[22] A. K. Horestani, C. Fumeaux, S. F. Al-Sarawi, and D. Abbott, "Displacement sensor based on diamond-shaped tapered split ring resonator," IEEE Sens. J., vol. 13, no. 4, pp. 1153-1160, 2013.

[23] I. M. Rusni, A. Ismail, A. R. H. Alhawari, M. N. Hamidon, and N. A. Yusof, "An aligned-gap and centered-gap rectangular multiple split ring resonator for dielectric sensing applications," Sensors (Switzerland), vol. 14, no. 7, pp. 13134-13148, 2014.

[24] P. Velez, J. Munoz-Enano, K. Grenier, J. Mata-Contreras, D. Dubuc, and F. Martin, "Split Ring Resonator-Based Microwave Fluidic Sensors for Electrolyte Concentration Measurements," IEEE Sens. J., vol. 19 , no. 7, pp. 2562-2569, 2019.

[25] W. Withayachumnankul, K. Jaruwongrungsee, A. Tuantranont, C. Fumeaux, and D. Abbott, "Metamaterial-based microfluidic sensor for dielectric characterization," Sensors Actuators, A Phys., vol. 189, pp. 233-237, 2013.

[26] A. Ebrahimi, W. Withayachumnankul, S. Al-Sarawi, and D. Aboott, "High-Sensitivity Metamaterial-Inspired Sensor," IEEE Sens. J, vol. 14, no. 14(5), pp. 1345-1351, 2014.

[27] P. Velez, L. Su, K. Grenier, J. Mata-Contreras, D. Dubuc, and F. Martin, "Microwave Microfluidic Sensor Based on a Microstrip Splitter/Combiner Configuration and Split Ring Resonators (SRRs) for Dielectric Characterization of Liquids," IEEE Sens. J., vol. 17, no. 20, pp. 6589-6598, 2017.

[28] A. Ebrahimi, J. Scott, and K. Ghorbani, "Ultrahigh-Sensitivity Microwave Sensor for Microfluidic Complex Permittivity Measurement," IEEE Trans. Microw. Theory Tech., vol. 67, no. 10, pp. 4269-4277, 2019.

[29] G. Govind and M. J. Akhtar, "Metamaterial-Inspired Microwave Microfluidic Sensor for Glucose Monitoring in Aqueous Solutions," IEEE Sens. J., vol. PP, no. c, pp. 1-1, 2019.

[30] C. Liu and F. Tong, "An SIW Resonator Sensor for Liquid Permittivity Measurements at C Band," IEEE Microw. Wirel. Components Lett., vol. 25, no. 11, pp. 751-753, 2015.

[31] E. Reyes-Vera, G. Acevedo-Osorio, M. Arias-Correa, and D. E. Senior, "A submersible printed sensor based on a monopole-coupled split ring resonator for permittivity characterization," Sensors (Switzerland), vol. 19, no. 8, 2019.

[32] G. Galindo-Romera, F. Javier Herraiz-Martínez, M. Gil, J. J. Martínez-Martínez, and D. Segovia-Vargas, "Submersible Printed Split-Ring Resonator-Based Sensor for Thin-Film Detection and Permittivity Characterization," IEEE Sens. J., vol. 16, no. 10, pp. 3587-3596, 2016.

[33] E. L. Chuma, Y. Iano, G. Fontgalland, and L. L. Bravo Roger, "Microwave sensor for liquid dielectric characterization based on metamaterial complementary split ring resonator," IEEE Sens. J., vol. 18, no. 24, pp. 9978-9983, 2018.

[34] "CST Microwave Studio." [Online]. Available: http://www.cst.com.

[35] J. D. Baena et al., "Equivalent-circuit models for split-ring resonators and complementary split-ring resonators coupled to planar transmission lines," IEEE Trans. Microw. Theory Tech., vol. 53, no. 4 II, pp. 1451-1460, 2005.

[36] A. A. Abduljabar, D. J. Rowe, A. Porch, and D. A. Barrow, "Novel microwave microfluidic sensor using a microstrip split-ring resonator," IEEE Trans. Microw. Theory Tech., vol. 62, no. 3, pp. 679-688, 2014.

[37] C.-S. Lee, B. Bai, Q.-R. Song, Z. Wang, and G.-F. Li, "Open Complementary Split-Ring Resonator Sensor for Dropping-Based Liquid Dielectric Characterization," IEEE Sens. J., vol. PP, no. c, pp. $1-1,2019$.

[38] J. Z. Bao, M. L. Swicord, and C. C. Davis, "Microwave dielectric characterization of binary mixtures of water, methanol, and ethanol," J. Chem. Phys., vol. 104, no. 12, pp. 4441-4450, 1996.

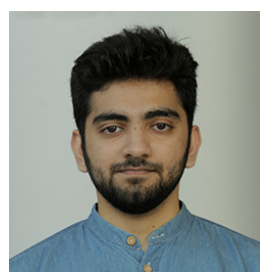

Ahmed Javed has received his B.Sc. in Electrical Engineering from Govt. College University (GCU), Lahore, in 2017. In 2019, he completed his M.Sc. in Electrical Engineering from Information Technology University (ITU), Lahore, and is working as a Research Intern at NanoTech Lab. His research interests include, dielectric characterization of materials, RF and microwave sensing, microwave circuit designing and meta-material inspired devices.

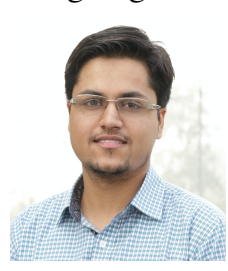

Ali Arif has received his B.Sc. in Electrical Engineering from the University of Central Punjab (UCP), Lahore, with the highest distinction in 2016. In 2018, he completed his M.Sc. in Electrical Engineering from Information Technology University (ITU), Lahore, and joined as a Research Associate at ITU NanoTech Lab. His research interests are in the field of applied electromagnetics, wearable antennas, Electromagnetic Band Gap (EBG) structures, and sensors for remote health monitoring systems.

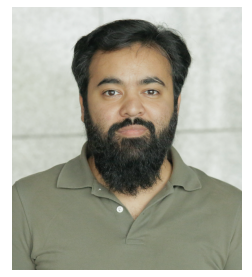

Muhammad Zubair (S'13-M'15) received his $\mathrm{Ph} . \mathrm{D}$. degree in electronic engineering from the Politecnico di Torino, Italy, in 2015. From 2015 to 2017, he was with the SUTD-MIT International Design Center, Singapore. Since 2017, he has been with Information Technology University, Lahore, Pakistan, as an Assistant Professor. His current research interests include charge transport, electron device modeling, computational electromagnetics, fractal electrodynamics, and microwave imaging. He serves as an Associate Editor for the IEEE Access, International Journal of Antennas and Propagation, PLOS One. and the IETMicrowaves, Antennas and Propagation (MAP). He is also the Principal Investigator (PI) of the Higher Education Commission (HEC), Pakistan TDF Grant.

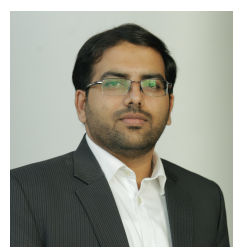

Muhammad Qasim Mehmood received his BS degree in Electronic Engineering from International Islamic University Islamabad in 2008. In 2010, he completed his MS in Electronic Engineering from Ghulam Ishaq Khan Institute, Pakistan. He completed his $\mathrm{PhD}$ from National University of Singapore, in January 2016, and joined Information Technology University (ITU), Lahore, Pakistan as an Assistant Professor. His current research interests are in the areas of optics and nano-photonics. electromagnetics, metamaterials, and antennas.

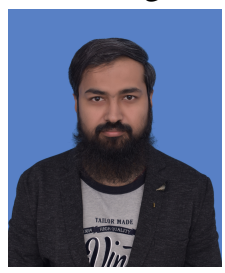

Kashif Riaz is an assistant professor in electrical engineering department of Information Technology University (ITU), Lahore, Pakistan. $\mathrm{He}$ is affiliated with Nanotech lab at ITU. He did his PhD from Hong Kong University of Science and Technology (HKUST). His current research work is focused on Micro/Nano ElectroMechanical Systems (MEMS/NEMS) using multidisciplinary approaches to develop innovative solutions for biomedical applications. 